\title{
Nuclear energy prospects and legal challenges towards achieving sustainable development goals
}

\author{
Marina Lizikova* \\ Institute of State and Law of the Russian Academy of Sciences, 10 Znamenka str, 119019,Moscow, \\ Russia
}

\begin{abstract}
This article examines the possible prospects for nuclear energy in achieving the sustainable development goals. Based on the analysis of the program and strategic documents of individual states, the current state is shown, recommended by the International Energy Agency and other international organizations as a direction for building cleaner and safer energy systems, for the production of small modular reactors in the world. Special attention is paid to the potential contribution of the latter to the economic, social and environmental development of the territories, as well as to the issues of legal regulation in relation to this type of installations.
\end{abstract}

\section{Introduction}

The concept of sustainable development, which originated in 1968, has undergone significant changes by now. The 2015 agreement of the UN member states "Transforming our world: the 2030 Agenda for Sustainable Development" [1] proclaimed new Sustainable Development Goals (SDGs), which are expected to be achieved by 2030 through joint efforts of states.

Achieving all, without exception, the Goals at all levels of sustainable development environmental, social and economic - is impossible without sustainable energy supply. Moreover, "ensuring a universal access to affordable, reliable, sustainable and modern energy sources for all" is designated as an independent Goal (No. 7), which provides for "expanding access to clean and safe fuels and technologies", "expanding the use of renewable sources energy" and "increasing the level of electrification".

The solution of these problems is of particular relevance in the context of an increase in the world's population, and, accordingly, an increase in energy consumption, deterioration of the environmental situation, as well as the need to stabilize the growth rate of the average annual temperature on the Earth, provided for by the provisions of the Paris Agreement on climate change [2]. This, in turn, dictates the need to increase the pace of transition to environmentally friendly low-carbon sources of electricity, especially wind and solar ones. However, according to the International Energy Agency (IEA) [3], it is impossible to fully

\footnotetext{
${ }^{*}$ Corresponding author: lizikova_m@mail.ru
} 
meet the world's electricity needs at the expense of exclusively renewable energy sources without negative consequences for energy security.

Nuclear power is another source of low-carbon electricity, which provides about $10 \%$ of the world's energy supply with virtually no CO2 emissions. According to the existing probable scenarios for achieving the Sustainable Development Goals [4-6], in terms of affordable clean energy and actions to combat climate change, it plays a significant role at the stage of transition to clean energy. Nevertheless, despite the unanimity regarding the sustainable development goals, the positions of states regarding the role of nuclear energy in achieving the latter differ. For example, in the United States, "Green New Deal" draft resolution has been submitted to Congress, which provides for a transition to $100 \%$ carbonfree energy with a complete rejection of nuclear energy. [7] Despite the refusal of certain European countries from nuclear energy (Germany, Sweden) or the obligation to reduce dependence on it (Spain, Switzerland, France), the EU Council decided not to exclude nuclear projects from sustainable "green" financing. [8] China, India and Russia, on the other hand, attach great importance to nuclear programs in the implementation of the sustainable development plan. There is also growing interest in nuclear energy from countries such as Indonesia, Jordan, Nigeria, the Philippines, Saudi Arabia and the United Republic of Tanzania. [9] A strong argument in favor of atomic energy on the part of newcomer states - countries planning to start or have already started implementing their own nuclear power program - is the close relationship between nuclear energy and the ability to meet national socio-economic needs (jobs, production and services with higher added cost), which undoubtedly contributes to the acceleration of economic growth.

In order to overcome the economic crisis, solving the problems of the global recession and rise in unemployment, and reducing the global greenhouse gas emissions, the International Energy Agency, together with the IMF, in a report published in June 2020, "Plan for Sustainable Recovery" [10], appealed to governments to build cleaner and safe energy systems. Stimulating innovation in small modular nuclear reactors to complement the existing large nuclear reactor technologies is proposed as a recommended policy and targeted investment.

Other international organizations are also in favor of deploying small modular reactors. In particular, the IAEA assigns them an important role in achieving the sustainable development goals. [11] The World Nuclear Association (NEA) is urging the countries to accelerate not only the deployment of large-scale reactors, but also to accelerate the development and commercialization of small modular reactors, whose role in decarbonization will increase in the 2030s and 2040s. [12] And according to the explanatory note to the report "The Role of Nuclear Energy in Sustainable Development: Ways of Solution" [9], designed to complement the report "Restructuring the Path to Uranium Resources - Application of the United Nations Framework Classification for Resources (UNFC) for the planning and implementation of sustainable uranium projects", Developed by the Working Group on Nuclear Fuel Resources in 2018, it will aim to support countries that have identified nuclear power, including small modular reactors, as a potential part of their energy portfolio.

\section{Materials and methods}

We used both, general scientific methods - analysis, synthesis, deduction and induction, dialectical and systemic method, and special legal methods - comparative legal, systemic and structural, historical and legal, etc. The method of formal-logical analysis is widely used. Based on the analysis of international treaties, statements and reports of international organizations, program and strategic documents of individual states, analysis of data on the current world energy situation, as well as scientific works of the experts, the author 
investigated the problems and prospects of the contribution of nuclear energy to the sustainable development in general, and the sustainable development particular territories, in particular, the issues of legal regulation in relation to nuclear power plants of low power have been investigated.

\section{Results and Discussion}

Small modular reactors are considered the commercial nuclear reactors with a capacity of $<300$ MW per reactor, the design feature of which is the use of new designs that have not been widely analyzed or licensed by the regulatory authorities, as well as modular structure, that is, the ability to add multiple reactors in close proximity to the same infrastructure. [13] Relatively small and flexible small modular reactors are manufactured in the factory, and then can be delivered and installed at the desired location.

Currently, according to the IAEA, there are about 50 designs and projects of small modular reactors in different stages of development in the world. [14]

A large-scale program for the introduction of small modular reactors is being implemented in Russia: KLT-40S, RITM-200 and RITM-200M reactors have been developed, 1 floating power unit with two KLT-40S reactors is in operation, the world's first floating nuclear power plant "Akademik Lomonosov" (FNPP) has been commissioned, it is planned to launch four RITM-200 reactors installed on the icebreakers "Sibir" and "Arktika" in 2020. An agreement was signed between Rosatom State Corporation and the Government of the Republic of Sakha (Yakutia) on interaction and cooperation in the construction of low-power nuclear power plants based on the newest RITM-200 reactor facility (2019). The energy strategy of the Russian Federation for the period up to 2035 [15] provides for the creation of low-capacity nuclear power plants for power supply of remote and isolated territories and is designated as one of the tasks facing the country's nuclear power industry. Tasks in the direction of "design and construction of reference power units of nuclear power plants, including nuclear power plants of low power", according to the Decree of the President of the Russian Federation dated 16.04.2020 No. 270 "On the development of equipment, technologies and research in the field of atomic energy use in the Russian Federation" [16], should be determined by the Comprehensive Program "Development of equipment, technologies and research in the field of atomic energy use in the Russian Federation for the period up to 2024" and resolved until 2024.

In Argentina and China, small modular reactors are in the final stages of construction or commissioning. In 2026, the United States plans to start a commercial operation of small modular reactors, and Canada's Small Modular Reactor Development Program provides for the launch of the demonstration reactors. The UK Nuclear Industry Development Program envisages the construction of the first modular reactor in 2030. The same deadline for putting the reactors into commercial operation appears in the Development Plan for Small Modular Reactors for the period 2017-2030 in Australia.

International cooperation in this area is also developing. Examples of the aforesaid: the Agreement on the Development of the Project for the Construction of a Small Modular Reactor of Russian Design in Jordan (2018) and the Memorandum of Intent on the PreFeasibility Study for the Construction of Small Power Plants in the Philippines (2019), signed by these countries with Russia, Memorandum of Understanding on Comprehensive Cooperation in Nuclear Research and Development, providing for cooperation on the commercialization of a small modular reactor of Korean design and the construction of the first such unit in Saudi Arabia, and the Agreement on the Establishment of a Joint Nuclear Energy Research Center in Saudi Arabia, signed by the Republic of Korea and Saudi Arabia in 2019, etc. 
Ability to alter the performance based on demand, mobility, wide design variability (design options exist for remote regions with less infrastructure, factory buildings, multimodule, mobile floating and seabed units), improved safety performance, more affordable price compared to large reactors, absence of air emissions - all this makes small modular reactors attractive for use in remote areas with less developed power grids. For example, the Australian and Canadian Small Modular Reactor Development Plans emphasize that such installations will improve the reliability of power supply to remote regions of Australia and northern Canada that use expensive diesel fuel, which will ensure energy independence for the latter, and will also contribute to the development of small businesses and improve living standards. Such reactors are suitable for the territories of the Russian North, the Far East, Kamchatka, Primorye, where fuel can be delivered only by air. For example, the "Akademik Lomonosov" floating nuclear power plant not only provides energy and heat to the Chukotka Autonomous Region, but also creates the conditions for increasing the pace of socio-economic development of the region and will become an important element of the infrastructure of the Northern Sea Route.

Such installations can be applied not only in northern regions, but also in small nonelectrified settlements in Africa.

Small modular reactors can be integrated with renewable energy sources, as well as used for purposes not related to the production of electricity, which, in turn, expands the possibilities of nuclear energy. For example, one of the intended uses for a plant in Argentina is water desalination. The offshore models of small modular reactors being developed by China are also planned to be used to meet the needs of island residents and oil rig personnel, not only for fresh drinking water, but also for heat. The high-temperature modular reactor being designed in South Africa can be used not only for desalination, but also for the production of hydrogen, fertilizers, metalworking and industrial heat supply in petrochemical and oil refineries.

The development of small modular rectors will create new jobs, intellectual property objects, build the supply chains, provide leadership in nuclear science and technology, stimulate innovation, emerge new industries, as well as fulfill the commitments to combat climate change and the transition to clean energy.

Summarizing the above factors of economic, social, ecological development of certain territories, potentially caused by the commissioning of small modular reactors, one should note not only their local nature, but also agree with T.D. Shchepetina, showing, using the example of Russia, that a low-power NPP system capable of ensuring, among other things, the territorial integrity and defense capability of the state, is also a factor of national security. [17]

Speaking at the plenary session of the IAEA General Conference on September 21, 2020, the General Director of Rosatom State Corporation A.Ye. Likhachev noted that the construction of low-capacity power units in the coming years could initiate a "new era in the global nuclear industry" and called for updating the existing international norms and rules in relation to low-power nuclear power plants. [18]

Indeed, despite the fact that research in the field of regulatory and legal regulation of low-power nuclear power plants since the early 2000s are in the center of attention of both the expert and the scientific community [19-21], nevertheless, the issues of applicability of existing norms of international law and IAEA safety standards to such installations due to:

- a variety of design and technological features of their projects;

- differences in potential conditions and modes of operation of these installations;

- lack of practical experience in the implementation of export (international) scenarios;

- the variety of deployment scenarios, as well as disaster planning issues arising from it;

- absence of specific rules governing the transportation of a nuclear reactor running on fuel; 
- need to maintain the optimal levels of nuclear safety, security, and non-proliferation when deploying small modular reactors in newcomer states;

- etc.,

currently continue to be relevant.

The status of small modular reactors as an innovative product, although the provisions of international conventions and IAEA standards governing large-scale nuclear power may be applied to them, still requires special legal regulation. Suggestions are put forward on the advisability of changing the existing global regime of international legal regulation in the format of separate multilateral agreements [20], on the development of adapted and flexible legal support for the deployment of such installations [22].

As H. Cook and F. Puente-Espel point out, legal and regulatory regimes must evolve simultaneously [23] in order to support regulation of nuclear and radiation safety, while at the same time fostering the technological innovation and guaranteeing a cost-effective and competitive way of deploying small modular reactors. A focus on establishing the regulatory control for small modular reactors is part of the objectives of the Small Modular Reactor Regulators Forum, founded by the IAEA in 2015. The results of the Forum are reflected in new recommendations on the safety implications of the modularity and compactness of small modular reactors, and on their life cycle licensing structure.

The existing differences in the national legal regulation of states in the field of the use of atomic energy, as well as the specifics of projects of small modular reactors, can complicate, delay their licensing and lead to the higher costs. The solution to this problem is seen in the need to harmonize the national requirements and guidelines, which will facilitate the adoption of more efficient, quick and informed decisions without compromising for the safety. One of the first examples of this is the Memorandum of Cooperation for the Further Optimization and Improvement of Regulation of Small Modular Reactors, signed in August 2019 between US and Canadian regulators. But there is also a more radical proposal to shift the regulatory paradigm towards licensing similar to the aviation industry, which is based on international standardization, harmonization of project approval procedures and change management.

\section{Conclusion}

Small modular reactors, due to their ability to generate clean and affordable energy, provide access to reliable power supply in remote and hard-to-reach areas, stimulate innovation, the development of energy-intensive industries and economic growth, can be seen as a promising tool in achieving the sustainable development goals and combating climate change. Despite the fact that the existing global international legal regulation is generally suitable for these facilities, the existing gaps can become an obstacle to achieving widespread deployment of this area of nuclear energy. This raises the question of creating a legal framework corresponding to the specifics of new technologies, the basis of which should be the fundamental security goals recognized throughout the world. The successful deployment of small modular reactors will also benefit from broad international cooperation in this area, as well as increased international coordination by the IAEA.

\section{References}

1. Sustainable Development Agenda, https://www.un.org/

2. Paris Agreement on Climate Change (2015), https://unfccc.int/

3. Nuclear Power in a Clean Energy System (2019), https://www.iea.org/ 
4. The Harmony Programme, Special Report: Global Warming of $1.5 \quad{ }^{\circ}$ C, https://www.world-nuclear.org, https://www.ipcc.ch/

5. Nuclear Power in a Clean Energy System (2019), https://www.iea.org/

6. M. Bunn, Nuclear Disarmament: A Critical Assessment, 185 (2019)

7. In the USA, a plan to switch to $100 \%$ carbon-free electricity generation is being discussed, https://www.atomic-energy.ru/

8. New EU rules agreed on 'green' investments, https://world-nuclear-news.org/

9. Conference Paper «The Role of Nuclear Energy in Sustainable Development: Entry Pathways», https://www.researchgate.net/

10. Sustainable Recovery: World Energy Outlook Special Report. Flagship report, (2020), https://www.iea.org/

11. World needs large and small reactors, Association says (2020), https://world-nuclearnews.org/

12. SMR Regulators' Forum Pilot Project Report: Considering the Application of a Graded Approach, Defence-in-Depth and Emergency Planning Zone Size for Small Modular Reactors (2018), https://www.iaea.org/

13. Small Modular Reactors: Global Perspectives: OVERVIEW, Atomic Expert, 2-3 (2019), http://atomicexpert.com/

14. On the Energy Strategy of the Russian Federation for the period up to 2035 of June 9, 2020, Order of the Government of the Russian Federation № 1523-r

15. On the development of engineering, technology and research in the field of atomic energy use in the Russian Federation of 16.04.2020, Decree of the President of the Russian Federation № 270

16. T.D. Shchepetina, Low-power NPP system as a factor of national security of Russia, http://www.proatom.ru/

17. Alexei Likhachev (Head of Rosatom), IAEA General Conference, http://innovrosatom.ru/

18. M. Lysenko, V. Bedenko, F. Dalno- ki-Veress,Moscow journal of international law, 3 (2019)

19. O. Supataeva, Development of International Legal Basis for Ensuring Safety and Priority Tasks of Russian Nuclear Legislation Improvement, Topical Issues of International Nuclear Law: Nuclear Safety: Proceedings of Symposium in the course of the "Atomexpo 2012", 229 (2012)

20. Collection of materials and results of research on the issues of legal and institutional support of transportable nuclear energy (2013).

21. H. Cook, F. Puente-Espel, Developing legal and regulatory frameworks for small modular nuclear reactors,https://uploads-ssl.webflow.com/ 